\title{
Early Pulmonary Interstitial Emphysema in Preterm Neonates-Respiratory Management and Case Report in Nonventilated Very Low Birth Weight Twins
}

\author{
Judith Gronbach, MD ${ }^{1}$ Harald Ehrhardt, MD ${ }^{1,2} \quad$ Klaus-Peter Zimmer, MD ${ }^{1} \quad$ Markus Waitz, MD ${ }^{1}$ \\ ${ }^{1}$ Department of General and Neonatology, Center for Pediatrics and \\ Youth Medicine, Justus Liebig University of Giessen, Germany \\ Address for correspondence Judith Gronbach, MD, Department of \\ General and Neonatology, Center for Pediatrics and Youth Medicine, \\ ${ }^{2}$ German Lung Research Center (DZL), Giessen, Germany \\ Justus Liebig University of Giessen, Feulgenstrasse 12, 35392 Giessen, \\ Germany (e-mail: judith.gronbach@paediat.med.uni-giessen.de).
} Am J Perinatol Rep 2018;8:e99-e105.

\author{
Abstract \\ Keywords \\ - pulmonary interstitial \\ emphysema \\ - very-low-birth-weight \\ infants \\ - noninvasive \\ ventilation \\ - surfactant \\ - antenatal steroids
}

Early pulmonary interstitial emphysema in extreme preterm neonates is closely linked with respiratory distress syndrome and exposure to mechanical ventilation. In severe cases, maintaining adequate gas exchange aiming to avoid further lung damage and other neonatal morbidities associated with systemic/pulmonary hypoperfusion, prolonged hypoxia, and respiratory acidosis can be challenging and requires in-depth knowledge into the pathophysiology of the disease. Herein, we report on very low birth weight twins who developed early pulmonary interstitial emphysema during noninvasive respiratory support. We further review the current evidence from the literature, specifically addressing on possible preventive measures and the respiratory management options of this acute pulmonary disease in high-risk neonates.

Despite the advances in neonatal pulmonology in last decades, neonatologists still encounter an acute pulmonary disease mainly associated with respiratory distress syndrome (RDS) and mechanical ventilation in very low birth weight infants (VLBWI), known as pulmonary interstitial emphysema (PIE). ${ }^{1}$ As a form of air leak syndrome, PIE is defined as the presence of entrapped air "bubbles" along the bronchovascular bundles resulting from a dissection of the interstitial or perivascular lung tissue. According to the distribution pattern and the time of occurrence, PIE can be classified as local or diffuse and acute or persistent. ${ }^{2}$ Pathophysiologically, the trapped gas progressively impairs pulmonary gas exchange by compressing functional lung tissue and reducing pulmonary blood flow. ${ }^{3}$ Management of consecutive hypoxemia and respiratory acidosis in PIE is challenging and may be aggravated by the development of pneumomediastinum, pneumothorax, or pneumopericardium. ${ }^{4}$ While older studies from the pre-surfactant era reported a high incidence of PIE (32\%) in VLBWI with RDS exposed to mechanical ventilation within the first

received

September 11, 2017 accepted after revision March 20, 2018
5 days of life, more recent data suggest a lower incidence (4.6\%). ${ }^{5,6}$ Early surfactant administration and the increased use of new ventilation modes may be attributable to this considerable reduction in PIE in the very preterm population. ${ }^{7,8}$ Although closely linked to mechanical ventilation, early emphysematic changes in VLBWI may occur even with the sole application of nasal continuous positive airway pressure (CPAP). ${ }^{9}$ Due to the increased use of noninvasive ventilation strategies and noninvasive surfactant administration techniques, we would like to present an uncommon case of VLBW twins who subsequently developed PIE during noninvasive respiratory support. We further discuss the etiopathology, potential preventive strategies, and the respiratory management in established PIE.

\section{Case Report}

Female diamniotic dichorionic twins were born to a 34-yearold first gravida at $28+5$ weeks of gestational age by C-
Copyright $\odot 2018$ by Thieme Medical Publishers, Inc., 333 Seventh Avenue, New York, NY 10001, USA. Tel: +1(212) 584-4662.
License terms

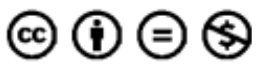

$10.1055 / \mathrm{s}-0038-1648253$ ISSN 2157-6998. 
section following premature rupture of the membranes (4 hours before delivery). Antenatal steroids were administered 2 weeks prior to delivery. The pregnancy was complicated by growth difference between the fetuses (selective intrauterine growth retardation) and gestational diabetes. There were no clinical symptoms, laboratory, or histological signs of chorioamnionitis. Serologies were all protective. The mother received an antibiotic course of Clindamycin for 1 week (vaginal swab specimen: Enterococcus faecalis, Escherichia coli, Streptococcus agalactiae). The parents were otherwise healthy.

Twin A. Apgar scores were 6 and 8 at 1 and 5 minutes, respectively. Birth weight was $1350 \mathrm{~g}$ (50th-75th centile). Delivery room management (as per our local hospital protocol for delivery room management of VLBWI) included nasal intermittent positive pressure ventilation (NIPPV), (settings: peak inspiratory pressure (PIP) $16 \mathrm{~cm} \mathrm{H}_{2} \mathrm{O}$, positive end expiratory pressure (PEEP) $8 \mathrm{~cm} \mathrm{H}_{2} \mathrm{O}, \mathrm{FiO}_{2}$ (fraction of inspired oxygen) 0.40 , respiratory rate (RR) $40 / \mathrm{min}$, inspiratory time (Ti) 0.3 second, flow restriction $101 / \mathrm{min}$ ). Empiric antibiotic treatment (ampicillin and gentamycin) was discontinued at day of life (DOL) 5 . Blood cultures remained sterile with negative $C$ reactive protein. Initially mild clinical symptoms for respiratory distress were noted and treated with NIPPV (nasal flaring, grunting, mild subcostal retractions). The chest X-ray (CXR) at 2 hours of age showed RDS grade I ( - Fig. 1A). At 6 hours of age, the infant received less invasive surfactant administration (120 mg Surfactant Curosurf suspension via 4 French umbilical vein catheter) for increased work of breathing (WOB) and high oxygen requirements $\left(\mathrm{FiO}_{2} 0.50\right)$. Post-surfactant, the infant remained stable on room air with nasal CPAP support. At 18 hours of life, a left-sided mild diffuse PIE was noted in the CXR (- Fig. 1B) which was treated with lateral decubital positioning and PEEP level reduction. At DOL 3, $\mathrm{FiO}_{2}$ suddenly increased to 0.50 with moderate WOB. CXR then revealed a ventral pneumothorax on the left side with mild mediastinal shift to the right ( $\mathbf{- F i g . 1 C}$ ), which was treated conservatively with left-side down positioning not modifying the respiratory support. $\mathrm{FiO}_{2}$ decreased to 0.30 with substantial clinical improvement and stable hemodynamic conditions
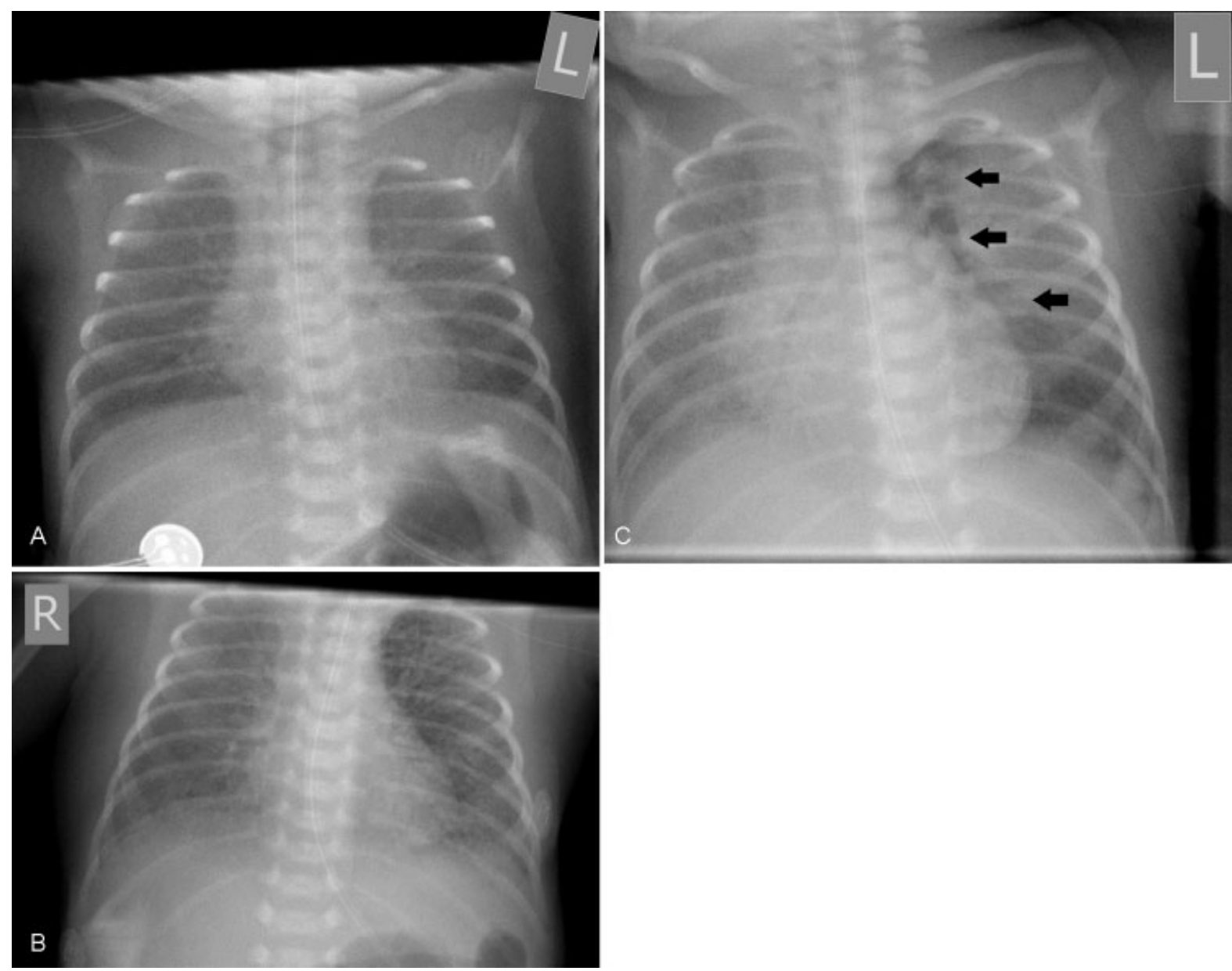

Fig. 1 Anterior-posterior chest X-rays, ventilator settings, interventions, and blood gas results of twin A case. (A) Two hours after birth. RDS picture grade $I^{\circ}$. Ventilator settings: NIPPV-Mode, PIP $16 \mathrm{~cm} \mathrm{H}_{2} \mathrm{O}, \mathrm{PEEP} 7 \mathrm{~cm} \mathrm{H} \mathrm{H}_{2} \mathrm{O}, \mathrm{RR} \mathrm{60/min,} \mathrm{FiO}_{2} 0.21$, Ti 0.3. Blood gas results (venous): $\mathrm{pH}$ 7.24, $p \mathrm{CO}_{2} 56 \mathrm{~mm} \mathrm{Hg}$. (B) Eighteen hours of life. Left-sided diffuse pulmonary interstitial emphysema. Ventilator settings: NIPPV-Mode, PIP $16 \mathrm{~cm} \mathrm{H}_{2} \mathrm{O}$, PEEP $7 \mathrm{~cm} \mathrm{H} \mathrm{H}_{2} \mathrm{O}$, RR $60 / \mathrm{min}, \mathrm{FiO}_{2}$ 0.21. Infant was further switched to CPAP-Mode and PEEP further dropped down to $5 \mathrm{~cm} \mathrm{H}_{2} \mathrm{O}$. (C) Forty-seven hours of life. Left-sided ventral pneumothorax (arrows), mild mediastinal shift to the right. Ventilator settings: CPAP-Mode, PEEP $7 \mathrm{~cm} \mathrm{H} \mathrm{H}_{2} \mathrm{O}, \mathrm{FiO}_{2}$ 0.3. Blood gas results (venous) pH 7.2, $p \mathrm{CO}_{2} 44 \mathrm{~mm} \mathrm{Hg}$. Abbreviations: $\mathrm{CPAP}$, continuous positive airway pressure; $\mathrm{FiO}_{2}$, fraction of inspired oxygen; NIPPV, noninvasive positive pressure ventilation; $\mathrm{PCO}_{2}$, partial pressure of oxygen; PEEP, positive end-expiratory pressure; PIP, positive inspiratory pressure; RDS, respiratory distress syndrome; RR, respiratory rate; Ti, inspiratory time. 
throughout the active stage of PIE. At DOL 7, twin A was transferred to the intermediate care unit on high-flow nasal cannula (flow 61/min, room air). According to the National Institutes of Health $(\mathrm{NIH})$ definition, the infant did not meet the criteria for BPD at 36 weeks gestational age (as per national institute of health definition). ${ }^{10}$ Additional examination findings were intraventricular hemorrhage (unilateral, right side, grade IV) and hyperbilirubinemia.

Twin B. Apgar scores were 7 at 1 and 9 at 5 minutes of age. Birth weight was $900 \mathrm{~g}$ (10th-25th centile). The infant was stabilized in the delivery room with NIPPV (PIP $16 \mathrm{~cm} \mathrm{H}_{2} \mathrm{O}$, PEEP $8 \mathrm{cmH}_{2} \mathrm{O}$, max. $\mathrm{FiO}_{2} 0.40$, Ti 0.3 second, flow restriction $101 / \mathrm{min}$ ). Birth weight was $900 \mathrm{~g}$ (10th-25th centile). Empiric antibiotic therapy was started (ampicillin, gentamycin) and discontinued after 5 days with negative blood cultures and tracheal aspirates. At 3 hours of life, the CXR demonstrated an RDS picture grade I (-Fig. 2A). The baby remained stable on NIPPV during the first 24 hours (PIP $14 \mathrm{~cm} \mathrm{H} \mathrm{H}_{2} \mathrm{O}$, PEEP $6 \mathrm{~cm} \mathrm{H}_{2} \mathrm{O}, \mathrm{FiO}_{2} 0.21$, Ti 0.3 second, RR of $60 / \mathrm{min}$ ). At the second $\mathrm{DOL}$, the twin required higher $\mathrm{FiO}_{2}$ during NIPPV and increased WOB. The following CXR showed a bilateral diffuse PIE ( $\mathbf{- F i g . ~ 2 B}$ ). Due to the progressive and severe oxygenation disorder $\left(\mathrm{FiO}_{2} 1.0\right)$ at 29 hours after birth, the infant received noninvasive surfactant $(120 \mathrm{mg}$ Surfactant Curosurf suspension via 4 French umbilical vein catheter). After a short improvement period, the infant deteriorated rapidly. At this stage, a tension pneumothorax on the right side with diffuse PIE on the left was diagnosed (-Fig. 2C) and emergency chest needling was performed with a peripheral intravenous cannula ( $G 20$, Vasofix, Braun, Germany). The infant was intubated and a chest tube (6 French Fuhrman, initial negative suction pressure $-30 \mathrm{~mm}$ $\mathrm{Hg}$, further reduced to $-10 \mathrm{~mm} \mathrm{Hg}$ ) was inserted into the right hemithorax (-Fig. 2D) and the baby was stabilized with conventional ventilation (synchronized intermittent mandatory ventilation, PIP $13 \mathrm{~cm} \mathrm{H}_{2} \mathrm{O}$, PEEP $4 \mathrm{~cm} \mathrm{H}_{2} \mathrm{O}, \mathrm{FiO}_{2} 0.45$, $\mathrm{RR} 80 / \mathrm{min}$, Ti 0.25$)$. Due to a progressive respiratory acidosis $\left(\mathrm{pH} 7.05, p \mathrm{CO}_{2} 91 \mathrm{~mm} \mathrm{Hg}\right.$ ), high-frequency oscillatory ventilation (HFOV) was initiated (-Fig. 2D). The neonate remained hemodynamically stable throughout the entire procedures and did not require any inotropic support. Respiratory support was further weaned (mean airway pressure $5 \mathrm{~cm} \mathrm{H}_{2} \mathrm{O}$, frequency 480/min, $\mathrm{FiO}_{2}$ 0.28) with improved ventilation ( $\mathrm{pH} 7.25, \mathrm{pCO}_{2} 47 \mathrm{~mm} \mathrm{Hg}$ ). The baby was eventually extubated to nasal CPAP (PEEP $5 \mathrm{~cm} \mathrm{H}_{2} \mathrm{O}, \mathrm{FiO}_{2}$ 0.3 ), and the chest tube removed prior to extubation. At DOL 8 , twin $B$ was transferred to the intermediate care unit on high-flow nasal cannula (flow $81 / \mathrm{min}$, room air). The followup CXR showed complete resolution of the interstitial emphysema ( - Fig. 2E). The infant developed a mild bronchopulmonary dysplasia (as per national institute of health definition). ${ }^{10}$

\section{Discussion}

In our two patients, clinical and radiological appearance of early PIE in VLBW twins with RDS occurred during exclusive noninvasive respiratory support. RDS in preterm neonates is a known risk factor for PIE, especially when treated with mechanical ventilation and the use of very high PIPs. ${ }^{11}$ However, several authors report on the spontaneous evolution of PIE in preterm neonates even in the absence of invasive ventilation, including a set of twin VLBWI. ${ }^{9,12-14}$ Prior to the development of PIE, all these cases reported in the literature had clinical and radiological signs of RDS, but were never treated with surfactant. Thus, it is unclear if mechanical ventilation is the main driver in the etiology of PIE or whether early PIE is rather the consequence of missed or delayed surfactant administration. Understanding the etiopathogenesis of this pulmonary disease is crucial and may have important implications in the respiratory management of RDS and PIE in the preterm population. Anatomical and functional airway characteristics in the early course of RDS are different as compared with other pulmonary diseases and may predispose VLBW to the development of early PIE. Ackermann et al hypothesized that in the surfactant deficient and structural immature lung, the compliance of the terminal gas exchange structures (i.e., the saccular and alveolar level) is reduced, while the airway compliance remains normal. ${ }^{15}$ This is supported by Reynolds et al who have shown that the terminal airways of deceased neonates treated with positive pressure ventilation for RDS were usually dilated, but the distal air saccules were not inflated. ${ }^{16}$ In the poorly recruited but ventilated lung, histology showed marked dilatation lesions of the bronchiolar and alveolar duct areas with the evidence of PIE in the lymphatic tissue around the pulmonary arteries. These findings suggest that the location of injury is the terminal conductive airway rather than alveolar or saccular rupture. ${ }^{16}$ Considering the above mentioned aspects, it seems conclusive that preventive and therapeutic strategies to improve lung compliance and reduce exposure to volutrauma, such as antenatal steroids, early surfactant administration, and the use of volume targeted ventilation modes in VLBW infants will eventually decrease the incidence of PIE. ${ }^{1,7,8}$ Of interest, two large studies assessing the effect of early CPAP, the COIN trial and a trial conducted by Rojas et al, reported a higher incidence of air leaks with the use of CPAP, ${ }^{6,17}$ whereas other trials (i.e., SUPPORT and CURPAP) with a similar design did not find this association. ${ }^{18,19}$ This might be explained by the different $\mathrm{FiO}_{2}$-intervention thresholds for intubation and surfactant administration $\left(\mathrm{FiO}_{2}>0.6\right.$ in the COIN and Rojas trial vs $\mathrm{FiO}_{2}>0.4$ in the SUPPORT and CURPAP study), where increased $\mathrm{FiO}_{2}$ requirements may indicate progression and severity of RDS. Results of a meta-analysis confirmed that a lower $\mathrm{FiO}_{2}$ threshold for surfactant administration $(\leq 0.45)$ decreased the incidence of air leaks in VLBWI. ${ }^{20}$ In our case report, twin A received noninvasive surfactant administration at 6 hours of life for increased WOB and oxygen requirements $\left(\mathrm{FiO}_{2}\right.$ 0.5). Despite the good clinical response to surfactant, the infant developed unilateral PIE at 18 hours of life. Twin B, however, had only mild clinical signs of RDS with no additional oxygen requirements throughout the first 24 hours of life, but subsequently deteriorated with severe bilateral diffuse PIE, consecutive pneumothorax, and the need for mechanical ventilation. Noninvasive surfactant 

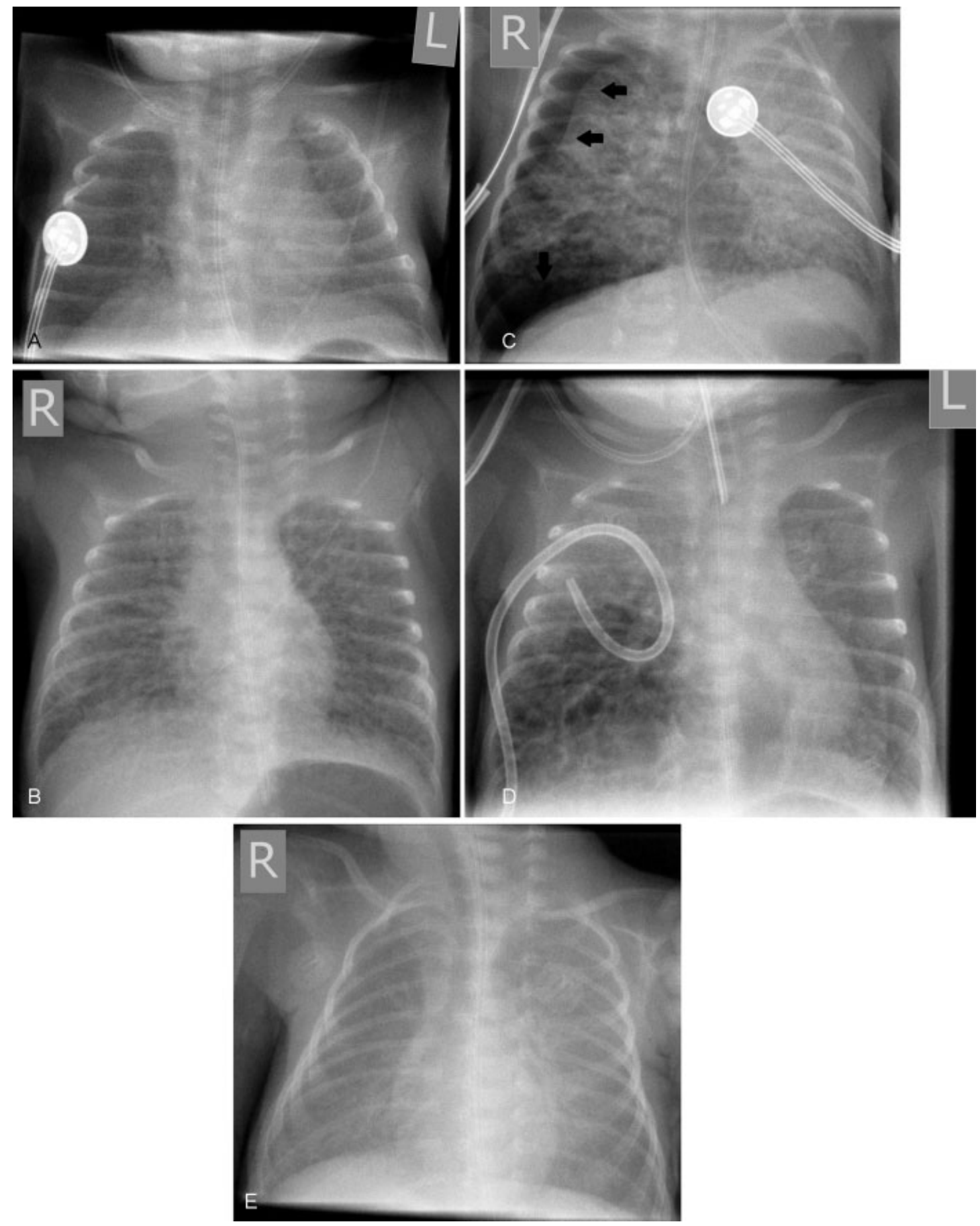

Fig. 2 Anterior-posterior chest X-rays, ventilator settings, interventions, and blood gas results of twin $B$ case. (A) Two hours after birth. RDS picture grade $I^{\circ}$. Ventilator settings: NIPPV-Mode, PIP $14 \mathrm{~cm} \mathrm{H}_{2} \mathrm{O}, \mathrm{PEEP} 6 \mathrm{~cm} \mathrm{H}_{2} \mathrm{O}, \mathrm{RR} \mathrm{60/min,} \mathrm{FiO}_{2} 0.21$, Ti 0.3. Blood gas results (venous): pH 7.34, $p \mathrm{CO}_{2} 44 \mathrm{~mm} \mathrm{Hg}$. (B) Twenty-six hours of life. Evolving bilateral and diffuse pulmonary interstitial emphysema. Ventilator settings: NIPPVMode, PIP $16 \mathrm{~cm} \mathrm{H}_{2} \mathrm{O}$, PEEP $6 \mathrm{~cm} \mathrm{H} \mathrm{H}_{2} \mathrm{O}$, RR 60/min, $\mathrm{FiO}_{2}$ 1.0, Ti 0.3. Blood gas results (venous): $\mathrm{pH} 7.22, p \mathrm{CO}_{2} 47 \mathrm{~mm} \mathrm{Hg}$. Infant received noninvasive surfactant administration and was switched to CPAP-Mode with PEEP $4 \mathrm{~cm} \mathrm{H}_{2} \mathrm{O}$. (C) Thirty-two hours of life. Right-sided tension pneumothorax (arrows) with mediastinal shifting to the left. Ventilator settings: CPAP-Mode, PEEP $4 \mathrm{~cm} \mathrm{H}_{2} \mathrm{O}$. Emergency chest-needling, intubation and chest tube insertion was performed and infant switched to conventional ventilation mode: SIMV, PIP $13 \mathrm{~cm} \mathrm{H}_{2} 0, P E E P 4 \mathrm{~cm} \mathrm{H} \mathrm{H}_{2} 0$, $\mathrm{FiO}_{2}$ 0.45, RR 80/min, Ti 0.25. Blood gas results (venous): $\mathrm{pH} 7.16, p \mathrm{CO}_{2} 63 \mathrm{~mm} \mathrm{Hg}$. (D) Seventy-seven hours of life. Intubated neonate with adequately drained pneumothorax, apical resolving PIE, and residual cysts in the basal lung segments. Note compression of left lung resulted in

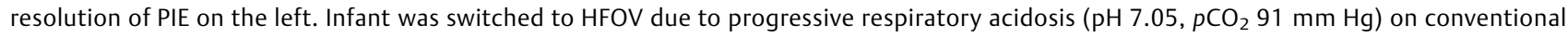
ventilation. Ventilator settings: $\mathrm{HFOV}$, mean airway pressure $8 \mathrm{~cm} \mathrm{H} \mathrm{H}_{2} \mathrm{O}$, frequency $480 / \mathrm{min}, \mathrm{FiO}_{2} 0.35$. (E) At day of life 11 . Complete resolution of PIE. Ventilator settings: High-flow nasal cannulas, flow $81 / \mathrm{min}, \mathrm{FiO}_{2} 0.21$. Abbreviations: $\mathrm{CPAP}$, continuous positive airway pressure; $\mathrm{FiO}_{2}$, fraction of inspired oxygen; HFOV, high frequency oscillation ventilation; NIPPV, noninvasive positive pressure ventilation; $p \mathrm{CO}_{2}$, partial pressure of oxygen; PEEP, positive end-expiratory pressure; PIE, pulmonary interstitial emphysema; PIP, positive inspiratory pressure; RDS, respiratory distress syndrome; RR, respiratory rate; SIMV, synchronized intermittent mandatory ventilation; Ti, inspiratory time. 
administration is increasingly used in VLBWI to avoid mechanical ventilation and has been used in both twins in our case report. ${ }^{21}$ In a recently conducted large multicenter trial by Kribs et al, the use of noninvasive surfactant application significantly reduced the incidence of pneumothoraces in a high-risk study population. ${ }^{22}$ Unfortunately, the authors did not specifically address on the incidence of PIE or the potential adverse event of unilateral surfactant administration, which might have occurred in twin A. We can only speculate that earlier treatment with surfactant might have prevented the development of PIE in our siblings. In fact, surfactant treatment during active PIE with severe respiratory failure, as applied in twin B, is not evidence based and, if anything, should be restricted to cases where other recommended treatment options (i.e., high-frequency ventilation modalities) are ineffective. With regard to the timing of surfactant therapy in both twins, one could argue that using the $\mathrm{FiO}_{2}$ as a single surrogate parameter for RDS severity may not adequately reflect the disease state and that the decision to treat with surfactant should be based on physiologic parameters $\left(\mathrm{FiO}_{2}\right)$ and reliable clinical scoring systems for RDS (i.e., Silverman score), as applied in the study by Kribs et $\mathrm{al}^{22,23}$ Although the twin status and the uncommon clinical course in both siblings may also point toward an infectious/inflammatory cause for PIE development, we did not find any clinical, microbiological, or laboratory evidence for chorioamnionitis or neonatal sepsis. ${ }^{24,25}$ Verma et al found that in utero exposure to high doses of magnesium sulfate (cumulative dose $>10 \mathrm{~g}$ ) is an independent risk factor for PIE in extremely low birth weight infants. ${ }^{26}$ In our case, the mother did receive a lower cumulative dose of magnesium sulfate (i.e., $5 \mathrm{~g}$ ).

The administration of antenatal corticosteroids (ANCS) has been shown to reduce the risk of morbidity and mortality for preterm neonates. Meta-analyses have demonstrated a lower risk of death, respiratory morbidity, intracranial hemorrhage, and necrotizing enterocolitis. ${ }^{27}$ The timing of ANCS relative to preterm birth appears to be crucial with the greatest benefit if delivery occurs $>24$ hours and $<7$ days. ${ }^{28}$ Benefits regarding the severity of RDS may dissipate after an interval of $>7$ days between ANCS administration and birth, particularly infants who received antenatal steroids $>14$ days prior to delivery. ${ }^{29}$ In our twin case report, there was a delay between ANCS administration and delivery of 14 days. Whether a second course or a single booster of ANCS is beneficial regarding the risk and severity of RDS remains controversial with conflicting results reported from the literature but no significant harm in early childhood either. ${ }^{30,31}$ Although the meta-analysis showed less need for mechanical ventilation in infants treated with ANCS, the incidence of any air leak syndromes was not significantly reduced. ${ }^{27}$

Respiratory management of established PIE is challenging and may include noninvasive and/or invasive ventilation strategies. In our view, stable respiratory and hemodynamic conditions justified a conservative management approach (nasal CPAP and lateral decubitus positioning) in twin A, while twin $B$ required distinct intensive care support due to the disease progression with tension pneumothorax and significant respiratory acidosis. Initially, the ventilation strategy in sibling B comprised of a reduction in mean airway pressure by dropping PEEP, PIP, shortening the Ti, and high RR ( - Fig. 2C). In theory, this should allow the interstitial air to escape and further avoid gas trapping while maintaining adequate expansion of the distal airways. ${ }^{32}$ However, clinical data regarding the potential benefits or harm of this approach are restricted to successful case series. ${ }^{32-34}$ Progressive respiratory acidosis in twin $\mathrm{B}$ forced us to switch the baby to HFOV with a rate of $480 / \mathrm{min}$. Measures of oxygenation and ventilation quickly improved thereafter (-Fig. 2D). HFOV has been proposed as a "lung protective" ventilation strategy in preterm neonates because it offers the benefit of adequate gas exchange using very low tidal volumes and lower mean airway pressures. ${ }^{35}$ In a large prospective case series, Squires et al reported on 19 cases of VLBWI with PIE (14 bilateral, 5 unilateral, respectively) that were managed with HFOV using very low oscillatory frequency of 300 to $360 /$ min for a minimum period of 24 hours. ${ }^{36}$ After transition to HFOV, a rapid and sustained improvement in oxygenation and ventilation was noted, particularly in the bilateral PIE group. Outcomes reported in the study were promising with a survival rate of $71 \%$ in the bilateral and $100 \%$ in the unilateral group. However, $90 \%$ of the survivors in the bilateral and $80 \%$ in the unilateral group were diagnosed with bronchopulmonary dysplasia. In our case report in twin B, we did not go down as low as a HFOV frequency of $480 / \mathrm{min}$ by reason of satisfying physiological responses at this rate. High frequency jet ventilation (HFJV), another mode of high frequency ventilation, appears to be the most promising ventilation strategy in preterm neonates with PIE. HFJV typically applies very short jet pulses (Ti $0.02-0.03$, rate of $400-450 / \mathrm{min}$ ), superimposed on a low continuous distending pressure, resulting in a prolonged expiratory cycle which may most effectively interrupt the pathogenesis of PIE. ${ }^{37}$ One randomized controlled multicenter trial in the early 90s compared HFJV versus rapid rate conventional ventilation in preterm infants with active PIE and found some benefits of HFJV regarding the resolution of PIE for $>24$ hours and radiographic improvement with no significant differences in the incidence of bronchopulmonary dysplasia or intraventricular hemorrhage. ${ }^{38}$ Notably, when survival resulting from rescue by the alternate therapy was excluded, survival rates were significantly higher in the HFJV group (64.9\% vs 47.1\%). Nevertheless, lack of availability of the HFJ ventilator limits its use, particularly in the Europe.

Further treatment options for PIE with very limited evidence and variable outcomes include selective main bronchial intubation for unilateral diseases and even more invasively, the creation of an artificial pneumothorax. . $^{39,40}$ Treatment of unilateral PIE by the use of Swan-Ganz catheter in unilateral PIE has also been successfully used and reported in the literature. ${ }^{41}$

\section{Conclusion}

Our case of PIE development during noninvasive ventilation in VLBW twins is in line with several other reports of preterm 
infants who have been treated with CPAP. The administration of antenatal steroids, invasive, and/or noninvasive surfactant treatment in the early course of RDS and the use of lung protective ventilation strategies (volume targeted ventilation) may decrease the incidence of PIE in high-risk neonates. Ventilation strategies during active PIE include noninvasive respiratory support in stable selected cases, while distinct clinical respiratory instability should be managed using either conventional ventilation with supraphysiological RRs and short Tis, HFOV with lower rates or HFJV, if available. Since CPAP/NIPPV and noninvasive surfactant administration is increasingly used in neonatal intensive care, clinical awareness for PIE should be paid to VLBW neonates with deteriorating respiratory conditions undergoing noninvasive respiratory support. We would further encourage investigators to specifically report on the incidence of PIE in future clinical trials dealing with neonatal pulmonary short- and long-term outcomes.

\section{Conflicts of Interest}

The authors declare no conflicts of interest.

Financial Disclosures

The authors have nothing to disclose.

\section{Funding Sources}

No external funding was secured for this article.

\section{Acknowledgment}

We are grateful to Dr. Brigitte Lemyre (Ottawa Hospital Research Institute, Ottawa, Ontario, Canada; Department of Pediatrics, Children's Hospital of Eastern Ontario, Ottawa, Ontario, Canada, CHEO Research Institute, Ottawa, Ontario, Canada), who reviewed the manuscript, for her valuable suggestions.

\section{References}

1 Hummler HD, Parys E, Mayer B, Essers J, Fuchs H, Schmid M. Risk indicators for air leaks in preterm infants exposed to restrictive use of endotracheal intubation. Neonatology 2015;108(01):1-7

2 Wilson JM, Mark EJ. Case records of the Massachusetts General Hospital. Weekly clinicopathological exercise. Case 30-1997 - a preterm newborn female triplet with diffuse cystic changes in the left lung. N Engl J Med 1997;337:2103-2116

3 Burnard ED, Gratton-Smith P, John E. A radiographic, pathologic and clinical study of interstitial emphysema complicating hyaline membrane disease. In: Stern L, Friss-Hansen B, Kildeberg P, eds. Intensive Care in the Newborn. New York: Masson; 1976:225-247

4 Thibeault DW, Lachman RS, Laul VR, Kwong MS. Pulmonary interstitial emphysema, pneumomediastinum, and pneumothorax. Occurrence in the newborn infant. Am J Dis Child 1973;126(05):611-614

5 Hart SM, McNair M, Gamsu HR, Price JF. Pulmonary interstitial emphysema in very low birthweight infants. Arch Dis Child 1983; 58(08):612-615

6 Morley CJ, Davis PG, Doyle LW, Brion LP, Hascoet JM, Carlin JB; COIN Trial Investigators. Nasal CPAP or intubation at birth for very preterm infants. N Engl J Med 2008;358(07):700-708

7 Bahadue FL, Soll R. Early versus delayed selective surfactant treatment for neonatal respiratory distress syndrome. Cochrane Database Syst Rev 2012;11:CD001456
8 Peng W, Zhu H, Shi H, Liu E. Volume-targeted ventilation is more suitable than pressure-limited ventilation for preterm infants: a systematic review and meta-analysis. Arch Dis Child Fetal Neonatal Ed 2014;99(02):F158-F165

9 Gürakan B, Tarcan A, Arda IS, Coşkun M. Persistent pulmonary interstitial emphysema in an unventilated neonate. Pediatr Pulmonol 2002;34(05):409-411

10 Jobe AH, Bancalari E. Bronchopulmonary dysplasia. Am J Respir Crit Care Med 2001;163(07):1723-1729

11 Morisot C, Kacet N, Bouchez MC, et al. Risk factors for fatal pulmonary interstitial emphysema in neonates. Eur J Pediatr 1990;149(07):493-495

12 Bawa P, Soontarapornchai K, Perenyi A, Goldfisher R, Amodio J. Development of localized pulmonary interstitial emphysema in a late preterm infant without mechanical ventilation. Case Rep Pediatr 2014;2014(14):429797

13 Al-Abdi SY, Singhal N. Pulmonary interstitial emphysema and continuous positive airway pressure in a premature infant. Saudi Med J 2005;26(10):1627-1629

14 Arioni C, Bellini C, Scopesi F, Mazzella M, Serra G. Pulmonary interstitial emphysema in preterm twins on continuous positive airway pressure. J Matern Fetal Neonatal Med 2006;19(10):671-673

15 Ackerman NB Jr, Coalson JJ, Kuehl TJ, et al. Pulmonary interstitial emphysema in the premature baboon with hyaline membrane disease. Crit Care Med 1984;12(06):512-516

16 Reynolds EO, Roberton NR, Wigglesworth JS. Hyaline membrane disease, respiratory distress, and surfactant deficiency. Pediatrics 1968;42(05):758-768

17 Rojas MA, Lozano JM, Rojas MX, et al; Colombian Neonatal Research Network. Very early surfactant without mandatory ventilation in premature infants treated with early continuous positive airway pressure: a randomized, controlled trial. Pediatrics 2009;123(01):137-142

18 Finer NN, Carlo WA, Walsh MC, et al; SUPPORT Study Group of the Eunice Kennedy Shriver NICHD Neonatal Research Network. Early CPAP versus surfactant in extremely preterm infants. N Engl J Med 2010;362(21):1970-1979

19 Sandri F, Plavka R, Ancora G, et al; CURPAP Study Group. Prophylactic or early selective surfactant combined with nCPAP in very preterm infants. Pediatrics 2010;125(06):e1402-e1409

20 Stevens TP, Harrington EW, Blennow M, Soll RF. Early surfactant administration with brief ventilation vs. selective surfactant and continued mechanical ventilation for preterm infants with or at risk for respiratory distress syndrome. Cochrane Database Syst Rev 2007;4(04):CD003063

21 Aldana-Aguirre JC, Pinto M, Featherstone RM, Kumar M. Less invasive surfactant administration versus intubation for surfactant delivery in preterm infants with respiratory distress syndrome: a systematic review and meta-analysis. Arch Dis Child Fetal Neonatal Ed 2017;102(01):F17-F23

22 Kribs A, Roll C, Göpel W, et al; NINSAPP Trial Investigators. Nonintubated surfactant application vs conventional therapy in extremely preterm infants: a randomized clinical trial. JAMA Pediatr 2015;169(08):723-730

23 Silverman WA, Andersen DH. A controlled clinical trial of effects of water mist on obstructive respiratory signs, death rate and necropsy findings among premature infants. Pediatrics 1956;17 (01):1-10

24 O'Donovan D, Wearden M, Adams J. Unilateral pulmonary interstitial emphysema following pneumonia in a preterm infant successfully treated with prolonged selective bronchial intubation. Am J Perinatol 1999;16(07):327-331

25 Fujimura M, Kitajima H, Nakayama M. Increased leukocyte elastase of the tracheal aspirate at birth and neonatal pulmonary emphysema. Pediatrics 1993;92(04):564-569

26 Verma RP, Chandra S, Niwas R, Komaroff E. Risk factors and clinical outcomes of pulmonary interstitial emphysema in extremely low birth weight infants. J Perinatol 2006;26(03):197-200 
27 Roberts D, Brown J, Medley N, Dalziel SR. Antenatal corticosteroids for accelerating fetal lung maturation for women at risk of preterm birth. Cochrane Database Syst Rev 2017;3:CD004454

28 Waters TP, Mercer B. Impact of timing of antenatal corticosteroid exposure on neonatal outcomes. J Matern Fetal Neonatal Med 2009;22(04):311-314

29 McEvoy C, Schilling D, Spitale P, Peters D, O'Malley J, Durand M. Decreased respiratory compliance in infants less than or equal to 32 weeks' gestation, delivered more than 7 days after antenatal steroid therapy. Pediatrics 2008;121(05):e1032-e1038

30 Peltoniemi OM, Kari MA, Tammela O, et al; Repeat Antenatal Betamethasone Study Group. Randomized trial of a single repeat dose of prenatal betamethasone treatment in imminent preterm birth. Pediatrics 2007;119(02):290-298

31 Crowther CA, McKinlay CJ, Middleton P, Harding JE. Repeat doses of prenatal corticosteroids for women at risk of preterm birth for improving neonatal health outcomes. Cochrane Database Syst Rev 2015;5(07):CD003935

32 Meadow WL, Cheromcha D. Successful therapy of unilateral pulmonary emphysema: mechanical ventilation with extremely short inspiratory time. Am J Perinatol 1985;2(03):194-197

$33 \mathrm{Ng}$ KP, Easa D. Management of interstitial emphysema by highfrequency low positive-pressure hand ventilation in the neonate. J Pediatr 1979;95(01):117-118

34 Gortner L, Pohlandt F, Bartmann P. [Treatment of unilateral spaceoccupying pulmonary interstitial emphysema with positioning measures and high-frequency ventilation] [Article in German]. Monatsschr Kinderheilkd 1988;136(08):432-435

35 Frantz ID III, Werthammer J, Stark AR. High-frequency ventilation in premature infants with lung disease: adequate gas exchange at low tracheal pressure. Pediatrics 1983;71(04):483-488

36 Squires KA, De Paoli AG, Williams C, Dargaville PA. High-frequency oscillatory ventilation with low oscillatory frequency in pulmonary interstitial emphysema. Neonatology 2013;104(04):243-249

37 Carlo WA, Siner B, Chatburn RL, Robertson S, Martin RJ. Early randomized intervention with high-frequency jet ventilation in respiratory distress syndrome. J Pediatr 1990;117(05):765-770

38 Keszler M, Donn SM, Bucciarelli RL, et al. Multicenter controlled trial comparing high-frequency jet ventilation and conventional mechanical ventilation in newborn infants with pulmonary interstitial emphysema. J Pediatr 1991;119(1 Pt 1):85-93

39 Chalak LF, Kaiser JR, Arrington RW. Resolution of pulmonary interstitial emphysema following selective left main stem intubation in a premature newborn: an old procedure revisited. Paediatr Anaesth 2007;17(02):183-186

40 Milligan DW, Issler $\mathrm{H}$, Massam M, Reynolds EO. Treatment of neonatal pulmonary interstitial emphysema by lung puncture. Lancet 1984;1(8384):1010-1011

41 Rastogi S, Gupta A, Wung JT, Berdon WE. Treatment of giant pulmonary interstitial emphysema by ipsilateral bronchial occlusion with a Swan-Ganz catheter. Pediatr Radiol 2007;37(11): $1130-1134$ 